Brain, Behavior and Evolution
Brain Behav Evol 2010;76:45-59

DOI: $10.1159 / 000319019$
Received: February 3,2010

Returned for revision: March 13, 2010 Accepted after revision: July 5, 2010

Published online: September 30, 2010

\title{
Cellular Scaling Rules for Primate Spinal Cords
}

\author{
Mark J. Burish $^{\mathrm{a}}$ J. Klint Peebles ${ }^{\mathrm{b}}$ Mary K. Baldwin ${ }^{\mathrm{c}}$ Luciano Tavares $^{\mathrm{d}}$ \\ Jon H. Kaas ${ }^{c}$ Suzana Herculano-Houzel ${ }^{d}$ \\ ${ }^{a}$ Neuroscience Graduate Program and Medical Scientist Training Program, Vanderbilt University, \\ ${ }^{b}$ Vanderbilt University, and ' Department of Psychology, Vanderbilt University, Nashville, Tenn., USA; \\ ${ }^{\mathrm{d}}$ Instituto de Ciências Biomédicas, Universidade Federal do Rio de Janeiro, Rio de Janeiro, Brazil
}

\section{Key Words}

Allometry $\cdot$ Number of neurons $\cdot$ Evolution $\cdot$ Connectivity

\begin{abstract}
The spinal cord can be considered a major sensorimotor interface between the body and the brain. How does the spinal cord scale with body and brain mass, and how are its numbers of neurons related to the number of neurons in the brain across species of different body and brain sizes? Here we determine the cellular composition of the spinal cord in eight primate species and find that its number of neurons varies as a linear function of cord length, and accompanies body mass raised to an exponent close to $1 / 3$. This relationship suggests that the extension, mass and number of neurons that compose the spinal cord are related to body length, rather than to body mass or surface. Moreover, we show that although brain mass increases linearly with cord mass, the number of neurons in the brain increases with the number of neurons in the spinal cord raised to the power of 1.7. This faster addition of neurons to the brain than to the spinal cord is consistent with current views on how larger brains add complexity to the processing of environmental and somatic information.

Copyright ๑ 2010 S. Karger AG, Basel
\end{abstract}

\section{Introduction}

Brain size varies across extant mammalian species by over 100,000-fold [Haug, 1987], and it has been known for almost a century that it correlates with body size in a manner that can be described mathematically. The relationship between brain size and body size can be expressed as a power function with an exponent that is usually smaller than 1 among orders [Jerison, 1955, 1973; Herculano-Houzel et al., 2006, 2007]. This means that brain size does not keep up with body size in larger animals although we have recently found that, for a subgroup of primates that includes humans, brain size is a linear function of body size [Herculano-Houzel et al., 2007; Azevedo et al., 2009]. Moreover, the precise exponent describing the body-brain size relationship is highly dependent on the species compared [Azevedo et al., 2009; Gabi et al., 2010, this issue], raising the possibility that, although related, brain size is not directly determined by body size, in contrast to what is often implied in studies that use body mass as an independent variable to predict brain size [e.g. Jerison, 1973; Marino, 1998].

The spinal cord, as an obligatory intermediary for most of the inputs and outputs that pass between the body and the brain [Passingham, 1975], is a component of the central nervous system (CNS), whose scaling rela-

Suzana Herculano-Houzel

Instituto de Ciências Biomédicas, UFRJ

Av. Carlos Chagas Filho, 373, Ilha do Fundão

Rio de Janeiro, RJ 21941-902 (Brazil)

Tel. +55 212562 6390, Fax +55 212290 0587, E-Mail suzanahh@ gmail.com 
tionship with both brain and body has been extensively debated. According to one proposition, the spinal cord is merely a somatic system of sensorimotor inputs and outputs while the brain is a system with a somatic component plus a nonsomatic component that relates to higher cognitive functions [Krompecher and Lipak, 1966], and thus spinal cord composition should scale as a linear function of body mass. According to another view, the sensorimotor inputs and outputs of the spinal cord are related directly to the surface area of the body, and thus spinal cord components should scale to body size as area to volume, that is, as a function of body size $e^{2 / 3}$ [Jerison, 1977; MacLarnon, 1996]. Alternatively, metabolic considerations such as the basal metabolic rate of the mother during gestation [Martin, 1981] or the amount of fat-free body mass [Schoenemann, 2004] would push the power exponent relating spinal cord composition to body mass to about $3 / 4$.

Previous studies of the spinal cord have focused on whole spinal cord weight and length [MacLarnon, 1996], spinal cord cross-sectional area [Fox and Wilczynski, 1986; MacLarnon, 1995], and specific pathways of the spinal cord [Towe, 1973; Nudo and Masterton, 1990; MacLarnon, 1995]. Little is known about the total number of neurons or other cells (nonneurons) in the spinal cord and how they relate to the brain and body. Recently, we determined the cellular composition of the brain of several primate species and found that brain mass across those species scales as a linear function of both the number of neurons in the brain and of body size [HerculanoHouzel et al., 2007]. Here we use the isotropic fractionator [Herculano-Houzel and Lent, 2005], a nonstereological method, to calculate the total number of neurons and nonneurons in the spinal cord and to determine how the cellular composition of the primate spinal cord scales with brain mass, number of neurons, and body mass, to test the hypotheses described above. A preliminary description of this work has been presented elsewhere [Burish et al., 2007].

\section{Materials and Methods}

\section{Animals}

We examined the spinal cords of 68 animals from 8 primate species and the closely related tree shrew. We used immunohistochemical staining for a detailed examination of cellular morphology in 11 animals from 4 primate species (galago, Otolemur garnetti, $\mathrm{n}=1$; common marmoset, Callithrix jacchus, $\mathrm{n}=1$; owl monkey, Aotus trivirgatus, $\mathrm{n}=1$; and rhesus macaque, Macaca mulatta, $\mathrm{n}=1$ ). We used isotropic fractionation [Herculano-Hou- zel and Lent, 2005] to explore the cellular composition in 57 animals from 9 species, including 8 primates (mouse lemur, Microcebus sp., $\mathrm{n}=1$; galago, O. garnetti, $\mathrm{n}=15$; common marmoset, $C$. jacchus, $\mathrm{n}=1$; owl monkey, $A$. trivirgatus, $\mathrm{n}=12$; squirrel monkey, Saimiri sciureus, $\mathrm{n}=4$; rhesus macaque, $M$. mulatta, $\mathrm{n}=5$; bonnet macaque, Macaca radiata, $\mathrm{n}=4$; and long-tailed macaque, $M a$ caca fascicularis, $\mathrm{n}=1$ ), and one nonprimate (tree shrew, Tupaia glis, $\mathrm{n}=13$ ) (table 1; individual data in online suppl. table 1, www. karger.com/10.1159/000319019). All animals were bred in animal housing, and all were adults or older juveniles based on birth records [Walker et al., 1983]. Gender information was obtained from veterinary records when available, and the body mass was measured within the final week before perfusion. All veterinary care and procedures were performed according to the ethical standards of the Vanderbilt Institutional Animal Care and Use Committee.

\section{Perfusion and Dissection}

Animals were given a lethal dose of sodium pentobarbital and, when areflexive, perfused transcardially with $0.9 \%$ phosphatebuffered saline (PBS, pH 7.4). Animals were then perfused with either 2 or $4 \%$ paraformaldehyde in PBS, usually followed by an equal amount of paraformaldehyde plus $10 \%$ sucrose in PBS. One M. mulatta (case 07-119) was perfused with $4 \%$ paraformaldehyde, $0.1 \%$ glutaraldehyde, and $0.25 \%$ picric acid in $0.2 \mathrm{M}$ phosphate buffer (PB, pH 7.4), and the mouse lemur was perfused with $\mathrm{PB}$ and then postfixed in $2 \%$ paraformaldehyde in PB. In all animals, the lamina and spinous processes of the vertebrae were removed along the entire length of the cord; the spinal roots were severed, and the spinal cord was removed and immersed in $4 \%$ paraformaldehyde for at least 14 days. After removal of the dura, brainstem, and cauda equina, the spinal cord was weighed and, in some cases, measured for length.

\section{Immunohistochemistry}

For examination of neurons using the isotropic fractionator method, we first needed to determine the suitability of our neuronal antibody in staining spinal cord neurons. We used antiNeuN mouse IgG (Chemicon, Temecula, Calif., USA), a neuronspecific antibody that stains all neurons in the CNS, with the exception of Purkinje cells, inferior olive cells, and mitral cells [Mullen et al., 1992]. Sections of cervical and lumbar spinal cord of $4 \mathrm{~mm}$ thickness were dissected and separated from the entire spinal cord and placed in PBS with 30\% sucrose solution for cryoprotection for $48 \mathrm{~h}$. The cervical and lumbar sections were then cut in the transverse plane at $20 \mu \mathrm{m}$ thickness on a freezing microtome and were saved in series depending on planned immunohistochemical staining procedures. Sections were rinsed in PBS at room temperature and then transferred to $0.2 \mathrm{M}$ boric acid and placed in an oven at $75^{\circ} \mathrm{C}$ for $2 \mathrm{~h}$. Afterwards, sections were incubated in $3 \%$ goat serum and $0.3 \%$ Triton in PBS for $1-2 \mathrm{~h}$, and then were immunoreacted overnight with anti-NeuN mouse IgG (1:2,000 in PBS) at room temperature. The following day, sections were rinsed and incubated in cyanine 3-conjugated anti-mouse IgG (1:400, Accurate Chemicals, Westbury, N.Y., USA), 5\% goat serum, 16\% 4',6-diamidino-2-phenylindole dihydrochloride (DAPI, Molecular Probes, Eugene, Oreg., USA, from a stock solution of $10 \mathrm{mg} / \mathrm{l}$, for visualization of all cell nuclei), and 79\% PBS for $1-2 \mathrm{~h}$ at room temperature. When the reaction was complete, sections were mounted on glass slides and cover slipped. Digital 
Table 1. Cellular composition of the spinal cord

\begin{tabular}{|c|c|c|c|c|c|c|c|c|c|c|c|c|c|c|}
\hline Species & $\mathrm{n}$ & $\mathrm{M}_{\mathrm{SC}}$ & $\mathrm{L}_{\mathrm{SC}}$ & $\% \mathrm{~N}_{\mathrm{SC}}$ & $\mathrm{N}_{\mathrm{SC}}$ & $\mathrm{O}_{\mathrm{SC}}$ & $\mathrm{D}_{\mathrm{N}}$ & $\mathrm{D}_{\mathrm{O}}$ & $\mathrm{M}_{\mathrm{BD}}$ & $\begin{array}{l}\mathrm{M}_{\mathrm{SC}} \% \\
\mathrm{M}_{\mathrm{BD}}\end{array}$ & $\mathrm{M}_{\mathrm{BR}}$ & $\begin{array}{l}\mathrm{M}_{\mathrm{SC}} \% \\
\mathrm{M}_{\mathrm{CNS}}\end{array}$ & $\mathrm{N}_{\mathrm{BR}}$ & $\begin{array}{l}\mathrm{N}_{\mathrm{SC}} \% \\
\mathrm{~N}_{\mathrm{CNS}}\end{array}$ \\
\hline Microcebus murinus & 1 & 0.235 & n.a. & 7.33 & 1.68 & 21.27 & 7,150 & 90,398 & 60.0 & 0.39 & 1.799 & 11.55 & 254.71 & 0.66 \\
\hline Tupaia glis & 14 & $\begin{array}{l}0.607 \pm \\
0.082\end{array}$ & $\begin{array}{l}102.92 \pm \\
3.70\end{array}$ & $\begin{array}{l}6.02 \pm \\
1.49\end{array}$ & $\begin{array}{l}2.69 \pm \\
0.71\end{array}$ & $\begin{array}{l}41.96 \pm \\
4.17\end{array}$ & $\begin{array}{l}4,529 \pm \\
1,597\end{array}$ & $\begin{array}{l}69,891 \pm \\
8,247\end{array}$ & $\begin{array}{l}173.9 \pm \\
26.0\end{array}$ & 0.35 & 2.752 & 18.07 & 261.40 & 1.02 \\
\hline Callithrix jacchus & 1 & 0.621 & n.a. & 7.57 & 3.65 & 44.55 & 5,875 & 71,734 & 340.0 & 0.18 & 7.780 & 7.39 & 635.80 & 0.57 \\
\hline Saimiri sciureus & 4 & $\begin{array}{l}1.602 \pm \\
0.078\end{array}$ & $\begin{array}{l}169.48 \pm \\
5.49\end{array}$ & $\begin{array}{l}4.83 \pm \\
1.75\end{array}$ & $\begin{array}{l}4.69 \pm \\
1.88\end{array}$ & $\begin{array}{l}91.24 \pm \\
6.88\end{array}$ & $\begin{array}{l}2,913 \pm \\
1,120\end{array}$ & $\begin{array}{l}56,888 \pm \\
1,614\end{array}$ & $\begin{array}{l}858.8 \pm \\
105.9\end{array}$ & 0.19 & 30.216 & 5.03 & $3,246.43$ & 0.14 \\
\hline Otolemur garnetti & 15 & $\begin{array}{l}1.528 \pm \\
0.292\end{array}$ & $\begin{array}{l}152.00 \pm \\
13.34\end{array}$ & $\begin{array}{l}6.14 \pm \\
1.29\end{array}$ & $\begin{array}{l}5.73 \pm \\
1.17\end{array}$ & $\begin{array}{l}88.47 \pm \\
14.60\end{array}$ & $\begin{array}{l}3,847 \pm \\
764\end{array}$ & $\begin{array}{l}59,593 \pm \\
10,308\end{array}$ & $\begin{array}{l}1,111.8 \pm \\
255.2\end{array}$ & 0.14 & 10.150 & 13.08 & 936.00 & 0.61 \\
\hline Aotus trivirgatus & 12 & $\begin{array}{l}2.131 \pm \\
0.526\end{array}$ & $\begin{array}{l}169.88 \pm \\
17.31\end{array}$ & $\begin{array}{l}6.11 \pm \\
1.12\end{array}$ & $\begin{array}{l}5.82 \pm \\
0.89\end{array}$ & $\begin{array}{l}91.00 \pm \\
14.81\end{array}$ & $\begin{array}{l}2,911 \pm \\
971\end{array}$ & $\begin{array}{l}44,202 \pm \\
7,980\end{array}$ & $\begin{array}{l}1,198.5 \pm \\
257.6\end{array}$ & 0.18 & 15.730 & 11.93 & $1,470.00$ & 0.39 \\
\hline Macaca fascicularis & 1 & 7.499 & n.a. & 3.06 & 11.38 & 360.62 & 1,518 & 48,090 & $5,700.0$ & 0.13 & 46.162 & 13.97 & $3,439.00$ & 0.33 \\
\hline Macaca radiata & 4 & $\begin{array}{l}7.842 \pm \\
2.317\end{array}$ & $\begin{array}{l}264.60 \pm \\
26.38\end{array}$ & $\begin{array}{l}2.50 \pm \\
0.11\end{array}$ & $\begin{array}{l}9.06 \pm \\
3.05\end{array}$ & $\begin{array}{l}335.94 \pm \\
110.72\end{array}$ & $\begin{array}{l}1,173 \pm \\
155\end{array}$ & $\begin{array}{l}45,664 \pm \\
3,911\end{array}$ & $\begin{array}{l}8,012.5 \pm \\
2,039.8\end{array}$ & 0.10 & 61.470 & 11.31 & $3,755.62$ & 0.24 \\
\hline Macaca mulatta & 5 & $\begin{array}{l}8.511 \pm \\
1.601\end{array}$ & $\begin{array}{l}247.46 \pm \\
15.23\end{array}$ & $\begin{array}{l}2.56 \pm \\
0.56\end{array}$ & $\begin{array}{l}10.00 \pm \\
2.95\end{array}$ & $\begin{array}{l}379.72 \pm \\
54.72\end{array}$ & $\begin{array}{l}1,176 \pm \\
1,597\end{array}$ & $\begin{array}{l}45,555 \pm \\
7,967\end{array}$ & $\begin{array}{l}84,700 \pm \\
2,452.4\end{array}$ & 0.10 & 87.346 & 8.88 & $6,380.00$ & 0.16 \\
\hline Variation & & $36 \times$ & & $3 \times$ & $6 \times$ & $18 \times$ & $6 \times$ & $2 \times$ & $141 \times$ & $4 \times$ & $48 \times$ & & $25 \times$ & \\
\hline
\end{tabular}

All values are given as mean \pm SD. $n=$ Number of individuals analyzed; $\mathrm{M}_{\mathrm{SC}}=$ average mass of spinal cord (in grams); $\mathrm{L}_{\mathrm{SC}}=$ average length of spinal cord (in millimeters); $\% \mathrm{~N}_{\mathrm{N}}=$ average percent of cells in the structure that are neurons; $\mathrm{N}_{\mathrm{SC}}=$ average number of neurons in the spinal cord (in millions); $\mathrm{O}_{\mathrm{SC}}=$ average number of other (nonneuronal) cells in the spinal cord (in millions); $\mathrm{D}_{\mathrm{N}}=$ average density of neurons per milligram of tissue in the spinal cord; $\mathrm{D}_{\mathrm{O}}=$ average density of other (nonneuronal) cells per milligram of tissue in the spinal cord; $\mathrm{M}_{\mathrm{BD}}=$ average body mass (in grams); $\mathrm{M}_{\mathrm{SC}} \% \mathrm{M}_{\mathrm{BD}}=$ relative mass of the spinal cord as a percentage of body mass (calculated from averages); $\mathrm{M}_{\mathrm{BR}}=$ average brain mass (in grams) [data from Herculano-Houzel et al., 2007, and Gabi et al., 2010]; $\mathrm{M}_{\mathrm{SC}} \% \mathrm{M}_{\mathrm{CNS}}=$ relative mass of the spinal cord as a percentage of CNS mass (brain + spinal cord; calculated from averages); $\mathrm{N}_{\mathrm{BR}}=$ average number of neurons in the brain (in millions) [data from Herculano-Houzel et al. 2007, and Gabi et al., 2008]; $\mathrm{N}_{\mathrm{SC}} \% \mathrm{~N}_{\mathrm{CNS}}=$ relative number of spinal cord neurons as a percentage of the number of CNS neurons (brain + spinal cord; calculated from averages); n.a. = nonavailable. images of processed sections were taken using a DXM120F digital camera mounted to a Nikon E800 microscope (Nikon Inc., Melville N.Y., USA). Photomicrographs were adjusted for brightness and contrast using Adobe Photoshop (Adobe Systems Inc.), but were otherwise not altered.

The neuronal identity of the NeuN-positive nuclei could be confirmed by their morphology in immunostained cryostat sections (fig. 1), which shows that the distribution of nuclei of neuronal morphology (all of which exhibit labeling for NeuN) agrees with the low percentages of NeuN-labeled nuclei found in the nuclear suspensions. Thus this antibody was deemed appropriate for use in the nuclear suspensions of the isotropic fractionator (see below).

\section{Fractionation}

The isotropic fractionator method [Herculano-Houzel and Lent, 2005] was used to estimate the total number of cells, neurons and nonneurons. Each spinal cord was mechanically homogenized in a detergent solution ( $40 \mathrm{~mm}$ sodium citrate and $1 \%$ Triton $\mathrm{X}-100)$. For analysis of total cell number, we added DAPI (Molecular Probes), a DNA-specific fluorescent dye that stains all cell nuclei, diluted $20-100 \times$ from a stock solution of $10 \mathrm{mg} / \mathrm{l}$. The suspension was kept homogeneous by agitation and four aliquots were placed on a hemocytometer and counted under a fluorescence microscope with $400 \times$ total magnification to determine the number of cells per milliliter of suspension. This number was then multiplied by the total suspension volume to determine the total number of cells in the original tissue. For analysis of total neuron number, a 1-ml sample of the DAPI-stained solution was centrifuged, washed by resuspension in PBS, centrifuged, resuspended in PBS and immunoreacted overnight with anti-NeuN mouse IgG (1:300). The next day, the nuclei were washed and then resuspended in a secondary antibody solution of cyanine 3-conjugated anti-mouse IgG (1:400), 10\% goat serum, 40\% DAPI, and $50 \%$ PBS. Nuclei were washed and then resuspended in PBS. An aliquot was placed on the hemocytometer; we counted at least 500 nuclei, noting how many were both DAPI positive and NeuN positive. The total number of neurons in the original tissue was calculated by applying the percentage of NeuN-positive neurons in our aliquot to the total number of cells; the total number of nonneurons was calculated by subtracting the total cell number by the total neuron number. The neuronal identity of the NeuN-positive nuclei could be confirmed by their morphology both in samples of the nuclear suspensions and in immunostained cryostat sections (fig. 1)

\section{Data Analysis}

Statistical analyses were performed in Statview (SAS Institute, Cary, N.C., USA) and Microsoft Excel (Microsoft Corporation, Redmond, Wash., USA). Correlations between variables were calculated using Spearman's correlation coefficient. When significant $(p<0.05)$, correlations were analyzed further by regression to power functions. The fits were considered significant for values of $\mathrm{p}<0.05$. Unless noted otherwise, all comparisons across species use the average values obtained for each species (table 1). 

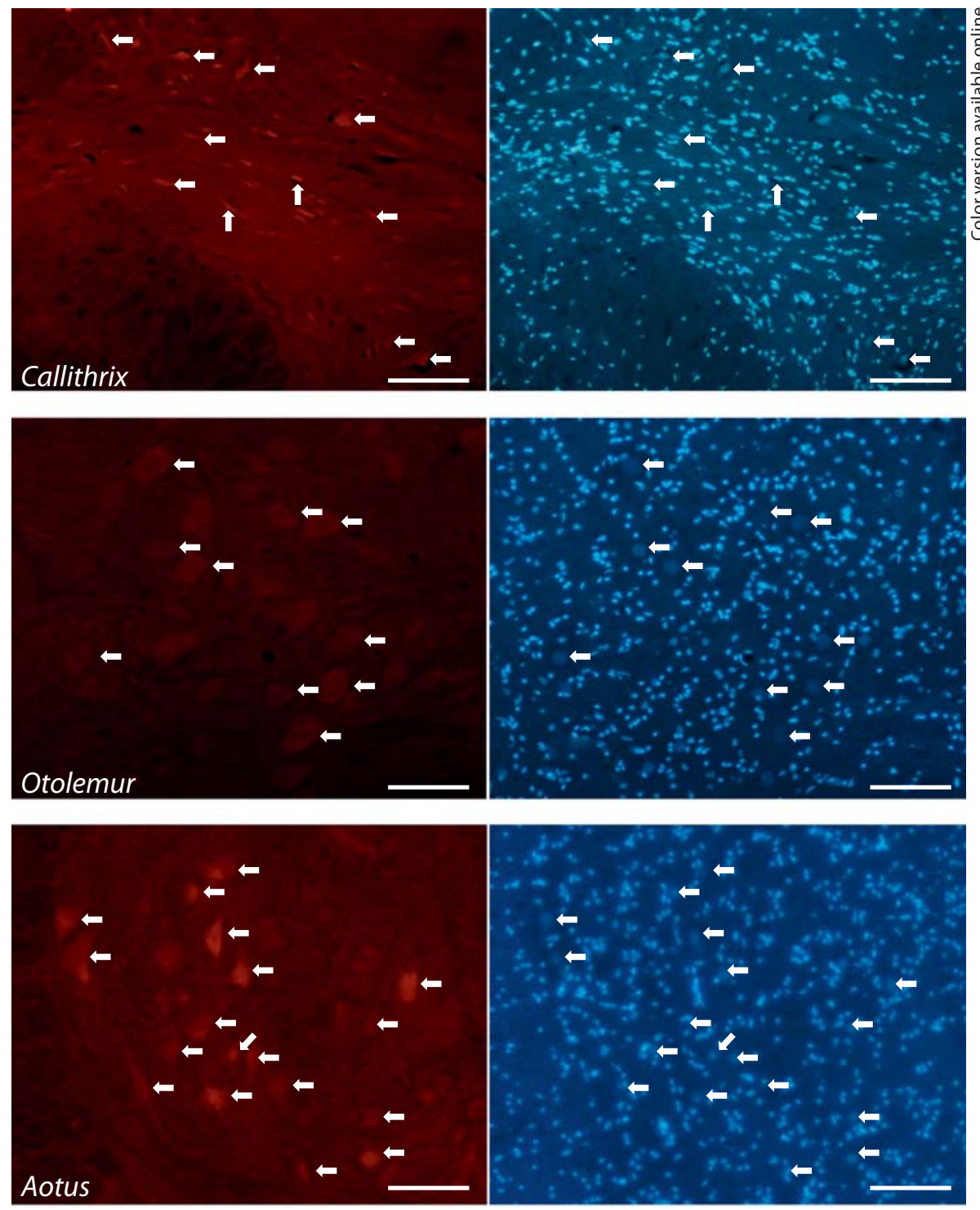

Fig. 1. Neuronal identity of NeuN-stained nuclei in the spinal cord is confirmed by nuclear morphology. Each pair of photomicrographs shows DAPI- and NeuNstained nuclei in the same field of immunostained transverse sections of the spinal cord of Callithrix, Otolemur, Aotus and $M$. mulatta. Arrows point to nuclei of clearly distinct morphology (either elongated, or very large and round, and always of low chromatin density). Notice that all DAPIstained nuclei of such morphology are also stained with NeuN. Bars: $100 \mu \mathrm{m}$.
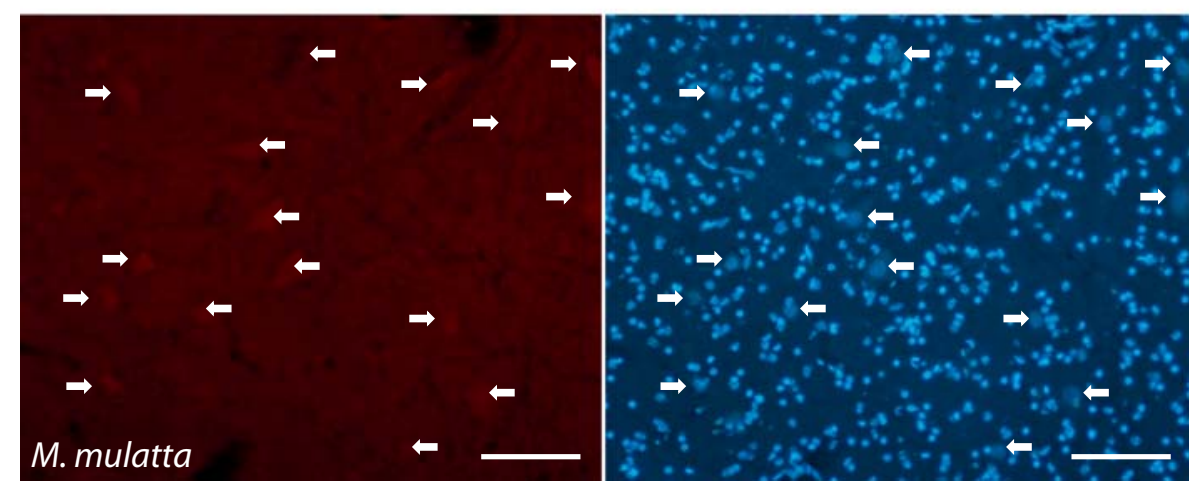
Phylogenetic independent contrasts were also calculated to examine the scaling of the brain and spinal cord as a function of the cellular composition of the spinal cord across the 8 primate and 1 Scandentia species while controlling for effects of phylogenetic relatedness in the dataset [Felsenstein, 1985]. Standardized independent contrasts were calculated using the PDAP:PDTREE module of Mesquite software version 2.7 [Maddison and Maddison, 2005]. Contrasts were calculated from log-transformed data. Phylogenies, shown in figure 2, are based on Purvis [1995] and Murphy et al. [2001a, b]. Branch lengths were transformed according to the method of Pagel [1992], which assigns all branch lengths to 1 with the constraint that tips are contemporaneous. The reported values for the linear regressions of independent contrasts on log-transformed data are reduced major axis (RMA) slope, $r^{2}$ and $p$ value, which are similar to the results obtained with least-square regression of independent contrasts for this dataset (table 2).

\section{Results}

We analyzed 57 spinal cord specimens from 8 primate species and 1 Scandentia species. Our list of primate species contains 3 species of closely related Old World monkeys ( $M$. mulatta, $M$. radiata and $M$. fascicularis), 3 species of New World monkeys, including both the Callithricidae radiation (C. jacchus) and the Cebidae radiation (A. trivirgatus and S. sciureus), and 2 species of prosimians, 1 from the Lorisiform radiation (O.r garnetti) and 1 from the Lemuriform radiation (Microcebus sp.; fig. 2, table 1). Since removal of the tree shrew (T. glis) from the analyses typically resulted in only minor changes, all scaling relationships presented hitherto apply to the 8 primate species combined with the closely-related tree shrew (see table 2 for comparison with relationships for primates only). Since scaling exponents were little affected by correcting for phylogenetic relatedness in the dataset (table 2), the exponents reported below refer to the uncorrected relationships.

\section{Spinal Cord Increases More Slowly than Body Mass}

Average body size in our data set (table 1) varies 141fold from the mouse lemur (60 g) to the rhesus macaque $(8,470 \mathrm{~g})$ whereas spinal cord mass varies 36 -fold, total cell number varies by 17 -fold and the number of neurons varies 6-fold. Spinal cord mass varies as a power function of body mass with an exponent of 0.733 , significantly below linearity (95\% confidence interval, CI, 0.652-0.813; fig. 3a). Although in a previous data set we found a sample of primates to have larger brains linearly proportional to body mass [Herculano-Houzel et al., 2007], for the current sample, we find that brain size increases as a similar power function of body mass to an exponent of 0.753 (CI, $0.559-$
0.947; fig. 3b). Accordingly, brain mass increases approximately linearly with spinal cord mass (exponent, 1.009; CI, 0.660-1.231). We find that the relative mass of the spinal cord, expressed as a percentage of body mass, decreases from $0.4 \%$ in the mouse lemur to $0.1 \%$ in the rhesus monkey (Spearman correlation $r=-0.950, p=0.0072$; table 1 ), varying as a power function of body mass raised to an exponent of -0.267 (CI, -0.348 to -0.187 ; table 2 ).

\section{Cellular Scaling Rules for Primate Spinal Cord}

The spinal cord gains mass faster than it gains neurons or nonneurons, proportionally to its total number of neurons raised to an exponent of 1.977 (CI, 1.601-2.354), and to the total number of nonneurons with an exponent of 1.222 (CI, 1.113-1.330; fig. 4a, b). The vast majority of the cells in the spinal cord are nonneuronal, with neurons representing fewer than $10 \%$ of cells for all species (table 1). This finding is in stark contrast to the primate brain where, using identical methods, the percentage of cells that are neurons was found to be $45 \%$ or greater [Herculano-Houzel et al., 2007]. Indeed, larger spinal cords are composed of a gradually smaller percentage of neurons (table 1), which varies as a power function of cord mass with an exponent of -0.317 ( $p=0.0005)$. Nonneurons increase at a faster rate than neurons in larger spinal cords (fig. 4c), with the ratio of nonneuronal to neuronal cells (NN/N ratio) increasing with spinal cord mass with an exponent of 0.333 ( $\mathrm{p}=0.0006)$, and spinal cord length with an approximately linear exponent $\left(\mathrm{r}^{2}=0.844, \mathrm{p}=\right.$ 0.0096).

\section{Spinal Cord Neuronal Composition Is Linearly \\ Related to Cord Length}

Spinal cord mass, as expected of a three-dimensional structure, increases in our sample approximately as the cube of one-dimensional cord length (raised to an exponent of 2.923; CI, 2.128-3.718; fig. 5a). Spinal cord length increases with body mass raised to an exponent of 0.230 significantly below $1 / 3$ (CI, 0.171-00.289; fig. 5b), which is consistent with the finding that body mass increases at a faster rate than spinal cord mass. Remarkably, the number of neurons in the spinal cord also varies with body mass raised to approximately the $1 / 3$ power (exponent $=0.360$; CI, $0.304-0.416$; fig. $6 \mathrm{a}$ ). The proximity to an exponent of $1 / 3$ suggests that the number of neurons in the spinal cord is linearly proportional to cord length. Indeed, we find that the number of neurons in the spinal cord increases linearly with cord length $\left(\mathrm{r}^{2}=0.918, \mathrm{p}=\right.$ 0.0026; fig. 6b), with approximately 43,000 neurons/mm of spinal cord. Accordingly, the average number of neu- 
Fig. 2. Phylogenetic relationship of the primate and Scandentia species analyzed. Average spinal cord, brain and body mass for each species are shown in parentheses. Phylogenetic relationships are based on Purvis [1995] and Murphy et al. [2001a, b].

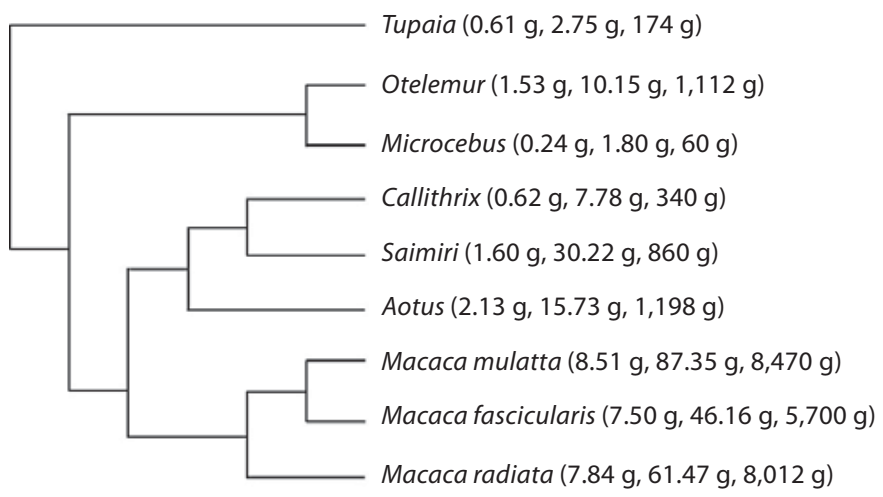

Table 2. Power laws that describe spinal cord scaling

\begin{tabular}{|c|c|c|c|c|c|c|c|c|}
\hline \multirow[t]{2}{*}{ Dep. var. } & \multirow{2}{*}{$\begin{array}{l}\text { Indep. } \\
\text { var. }\end{array}$} & \multicolumn{3}{|l|}{ Primates only } & \multicolumn{4}{|l|}{ Primates and tree shrew } \\
\hline & & power law & $\begin{array}{l}\mathrm{p} \text { value, } \\
\text { exponent }\end{array}$ & $95 \% \mathrm{CI}$ & power law & $\begin{array}{l}\mathrm{p} \text { value } \\
\text { exponent }\end{array}$ & $95 \% \mathrm{CI}$ & $\begin{array}{l}\text { phylogeny- } \\
\text { corrected } \\
\text { exponent }\end{array}$ \\
\hline $\mathrm{M}_{\mathrm{SC}}$ & $\mathrm{M}_{\mathrm{BD}}$ & $\mathrm{M}_{\mathrm{SC}}=0.009 \times \mathrm{M}_{\mathrm{BD}}^{0.754}$ & $<0.0001$ & $0.673-0.835$ & $\mathrm{M}_{\mathrm{SC}}=0.011 \times \mathrm{M}_{\mathrm{BD}}^{0.733}$ & $<0.0001$ & $0.652-0.813$ & 0.709 \\
\hline $\mathrm{M}_{\mathrm{BR}}$ & $\mathrm{M}_{\mathrm{BD}}$ & $\mathrm{M}_{\mathrm{BR}}=0.110 \times \mathrm{M}_{\mathrm{BD}}^{0.717}$ & 0.0002 & $0.500-0.934$ & $\mathrm{M}_{\mathrm{BR}}=0.081 \times \mathrm{M}_{\mathrm{BD}}^{0.753}$ & $<0.0001$ & $0.559-0.947$ & 0.723 \\
\hline $\mathrm{M}_{\mathrm{BR}}$ & $\mathrm{M}_{\mathrm{SC}}$ & $\mathrm{M}_{\mathrm{BR}}=9.393 \times \mathrm{M}_{\mathrm{SC}} 0.946$ & 0.0002 & $0.660-1.231$ & $\mathrm{M}_{\mathrm{BR}}=8.311 \times \mathrm{M}_{\mathrm{SC}}^{1.009}$ & $<0.0001$ & $0.716-1.303$ & 1.020 \\
\hline $\mathrm{M}_{\mathrm{SC}} \% \mathrm{M}_{\mathrm{BD}}$ & $\mathrm{M}_{\mathrm{BD}}$ & $\mathrm{M}_{\mathrm{SC}} \% \mathrm{M}_{\mathrm{BD}}=0.934 \times \mathrm{M}_{\mathrm{BD}}^{-0.246}$ & 0.0003 & $-0.327-0.165$ & $\mathrm{M}_{\mathrm{SC}} \% \mathrm{M}_{\mathrm{BD}}=1.117 \times \mathrm{M}_{\mathrm{BD}}^{-0.267}$ & 0.0001 & $-0.348-0.187$ & -0.320 \\
\hline $\mathrm{M}_{\mathrm{SC}}$ & $\mathrm{N}_{S C}$ & $\mathrm{M}_{\mathrm{SC}}=4.285 \times 10^{-14} \times \mathrm{N}_{\mathrm{SC}}^{2.028}$ & $<0.0001$ & $1.591-2.465$ & $\mathrm{M}_{\mathrm{SC}}=9.719 \times 10^{-14} \times \mathrm{N}_{\mathrm{SC}}^{1.977}$ & $<0.0001$ & $1.601-2.354$ & 1.829 \\
\hline $\mathrm{M}_{\mathrm{SC}}$ & $\mathrm{O}_{\mathrm{SC}}$ & $\mathrm{M}_{\mathrm{SC}}=2.996 \times 10^{-10} \times \mathrm{NN}_{\mathrm{SC}}^{1.221}$ & $<0.0001$ & $1.093-1.350$ & $\mathrm{M}_{\mathrm{SC}}=2.971 \times 10^{-10} \times \mathrm{O}_{\mathrm{SC}}^{1.222}$ & $<0.0001$ & $1.113-1.330$ & 1.278 \\
\hline $\mathrm{O}_{\mathrm{SC}}$ & $\mathrm{N}_{\mathrm{SC}}$ & $\mathrm{O}_{\mathrm{SC}}=0.001 \times \mathrm{N}_{\mathrm{SC}}^{1.639}$ & $<0.0001$ & $1.228-2.050$ & $\mathrm{O}_{\mathrm{SC}}=0.002 \times \mathrm{N}_{\mathrm{SC}}^{1.600}$ & $<0.0001$ & $1.250-1.949$ & 1.455 \\
\hline $\mathrm{O} / \mathrm{N}_{\mathrm{SC}}$ & $\mathrm{M}_{\mathrm{SC}}$ & $\mathrm{O} / \mathrm{N}_{\mathrm{SC}}=16.578 \times \mathrm{M}_{\mathrm{SC}}{ }^{0.346}$ & 0.0015 & $0.193-0.500$ & $\mathrm{O} / \mathrm{N}_{\mathrm{SC}}=17.011 \times \mathrm{M}_{\mathrm{SC}}{ }^{0.333}$ & 0.0006 & $0.198-0.467$ & 0.345 \\
\hline$\% \mathrm{~N}_{\mathrm{SC}}$ & $\mathrm{M}_{\mathrm{SC}}$ & $\% \mathrm{~N}_{\mathrm{SC}}=5.855 \times \mathrm{M}_{\mathrm{SC}}{ }^{-0.329}$ & 0.0013 & $-0.472-0.186$ & $\% \mathrm{~N}_{\mathrm{SC}}=5.727 \times \mathrm{M}_{\mathrm{SC}}{ }^{-0.317}$ & 0.0005 & $-0.442-0.193$ & -0.305 \\
\hline $\mathrm{N}_{\mathrm{SC}}$ & $\mathrm{M}_{\mathrm{BD}}$ & $\mathrm{N}_{\mathrm{SC}}=4.26 \times 10^{6} \times \mathrm{M}_{\mathrm{BD}}^{0.346}$ & 0.0015 & $0.291-0.427$ & $\mathrm{~N}_{\mathrm{SC}}=4.23 \times 10^{6} \times \mathrm{M}_{\mathrm{BD}}^{0.360}$ & $<0.0001$ & $0.304-0.416$ & 0.388 \\
\hline $\mathrm{O}_{\mathrm{SC}}$ & $\mathrm{L}_{\mathrm{SC}}$ & $\mathrm{O}_{\mathrm{SC}}=28.645 \times \mathrm{L}_{\mathrm{SC}}{ }^{2.940}$ & 0.0048 & $1.706-4.174$ & $\mathrm{O}_{\mathrm{SC}}=453.166 \times \mathrm{L}_{\mathrm{SC}}^{2.424}$ & 0.0014 & $1.564-3.285$ & 2.646 \\
\hline $\mathrm{M}_{\mathrm{SC}}$ & $\mathrm{L}_{\mathrm{SC}}$ & $\mathrm{M}_{\mathrm{SC}}=6.218 \times 10^{-8} \times \mathrm{L}_{\mathrm{SC}}^{3.367}$ & 0.0031 & $2.151-4.582$ & $\mathrm{M}_{\mathrm{SC}}=6.687 \times 10^{-7} \times \mathrm{L}_{\mathrm{SC}}{ }^{2.923}$ & 0.0005 & $2.128-3.718$ & 3.051 \\
\hline $\mathrm{L}_{\mathrm{SC}}$ & $\mathrm{M}_{\mathrm{BD}}$ & $\mathrm{L}_{\mathrm{SC}}=37.406 \times \mathrm{M}_{\mathrm{BD}}^{0.213}$ & 0.0074 & $0.108-0.317$ & $\mathrm{~L}_{\mathrm{SC}}=32.534 \times \mathrm{M}_{\mathrm{BD}}^{0.230}$ & 0.0004 & $0.171-0.289$ & 0.229 \\
\hline $\mathrm{D}_{\mathrm{N}}$ & $\mathrm{M}_{\mathrm{SC}}$ & $\mathrm{D}_{\mathrm{N}}=4004.128 \times \mathrm{M}_{\mathrm{SC}}^{-0.527}$ & $<0.0001$ & $-0.634-0.420$ & $\mathrm{D}_{\mathrm{N}}=3914.558 \times \mathrm{M}_{\mathrm{SC}}-0.515$ & $<0.0001$ & $-0.611-0.420$ & -0.493 \\
\hline $\mathrm{D}_{\mathrm{O}}$ & $\mathrm{M}_{\mathrm{SC}}$ & $\mathrm{D}_{\mathrm{O}}=64094.855 \times \mathrm{M}_{\mathrm{SC}}{ }^{-0.181}$ & 0.0013 & $-0.260-0.102$ & $\mathrm{D}_{\mathrm{O}}=64055.724 \times \mathrm{M}_{\mathrm{SC}}{ }^{-0.181}$ & 0.0004 & $-0.247-0.114$ & -0.232 \\
\hline $\mathrm{M}_{\mathrm{CX}}$ & $\mathrm{M}_{\mathrm{SC}}$ & $\mathrm{M}_{\mathrm{CX}}=5.993 \times \mathrm{M}_{\mathrm{SC}}^{1.049}$ & 0.0002 & $0.728-1.371$ & $\mathrm{M}_{\mathrm{CX}}=5.187 \times \mathrm{M}_{\mathrm{SC}}^{1.124}$ & $<0.0001$ & $0.789-1.460$ & 1.115 \\
\hline $\mathrm{M}_{\mathrm{CB}}$ & $\mathrm{M}_{\mathrm{SC}}$ & $\mathrm{M}_{\mathrm{CB}}=1.241 \times \mathrm{M}_{\mathrm{SC}}^{0.795}$ & 0.0006 & $0.500-1.089$ & $\mathrm{M}_{\mathrm{CB}}=1.066 \times \mathrm{M}_{\mathrm{SC}}^{0.874}$ & 0.0004 & $0.550-1.198$ & 0.896 \\
\hline $\mathrm{M}_{\mathrm{RA}}$ & $\mathrm{M}_{\mathrm{SC}}$ & $\mathrm{M}_{\mathrm{RA}}=1.837 \times \mathrm{M}_{\mathrm{SC}} 0.677$ & 0.0009 & $0.402-0.952$ & $\mathrm{M}_{\mathrm{RA}}=1.734 \times \mathrm{M}_{\mathrm{SC}} 0.707$ & 0.0003 & $0.461-0.953$ & 0.824 \\
\hline $\mathrm{N}_{\mathrm{BR}}$ & $\mathrm{N}_{\mathrm{SC}}$ & $\mathrm{N}_{\mathrm{BR}}=0.064 \times \mathrm{N}_{\mathrm{SC}}^{1.543}$ & 0.0031 & $0.750-2.337$ & $\mathrm{~N}_{\mathrm{BR}}=0.006 \times \mathrm{N}_{\mathrm{SC}}^{1.689}$ & 0.0009 & $0.965-2.414$ & 1.658 \\
\hline $\mathrm{N}_{\mathrm{SC}} \% \mathrm{~N}_{\mathrm{CNS}}$ & $\mathrm{M}_{\mathrm{CNS}}$ & $\mathrm{N}_{\mathrm{SC}} \% \mathrm{~N}_{\mathrm{CNS}}=1.071 \times \mathrm{M}_{\mathrm{CNS}}-0.380$ & 0.0147 & $-0.654-0.106$ & $\mathrm{~N}_{\mathrm{SC}} \% \mathrm{~N}_{\mathrm{CNS}}=1.280 \times \mathrm{M}_{\mathrm{CNS}}{ }^{-0.427}$ & 0.0034 & $-0.659-0.194$ & -0.552 \\
\hline $\mathrm{N}_{\mathrm{CX}}$ & $\mathrm{N}_{\mathrm{SC}}$ & $\mathrm{N}_{\mathrm{CX}}=1.354 \times 10^{-5} \times \mathrm{N}_{\mathrm{SC}}^{2.003}$ & 0.0063 & $0.809-3.198$ & $\mathrm{~N}_{\mathrm{CX}}=2.393 \times 10^{-6} \times \mathrm{N}_{\mathrm{SC}}^{2.112}$ & 0.0017 & $1.099-3.124$ & 2.231 \\
\hline $\mathrm{N}_{\mathrm{CB}}$ & $\mathrm{N}_{S C}$ & $\mathrm{~N}_{\mathrm{CB}}=0.129 \times \mathrm{N}_{\mathrm{SC}}^{1.473}$ & 0.0024 & $0.758-2.188$ & $\mathrm{~N}_{\mathrm{CB}}=0.012 \times \mathrm{N}_{\mathrm{SC}}^{1.621}$ & 0.0007 & $0.952-2.289$ & 1.613 \\
\hline $\mathrm{N}_{\mathrm{RA}}$ & $\mathrm{N}_{\mathrm{SC}}$ & $\mathrm{N}_{\mathrm{RA}}=5.694 \times \mathrm{N}_{\mathrm{SC}}^{1.018}$ & 0.0105 & $0.338-1.699$ & $\mathrm{~N}_{\mathrm{RA}}=8.185 \times \mathrm{N}_{\mathrm{SC}}{ }^{0.996}$ & 0.0041 & $0.432-1.559$ & 0.979 \\
\hline
\end{tabular}

$\mathrm{M}_{\mathrm{SC}}=$ Average mass of spinal cord (in grams); $\mathrm{L}_{\mathrm{SC}}=$ average length of spinal cord (in millimeters); $\% \mathrm{~N}_{\mathrm{N}}=$ average percent of cells in the structure that are neurons; $\mathrm{N}_{\mathrm{SC}}=$ average number of neurons in the spinal cord (in millions); $\mathrm{O}_{\mathrm{SC}}=$ average number of other (nonneuronal) cells in the spinal cord (in millions); $\mathrm{D}_{\mathrm{N}}=$ average density of neurons per milligram of tissue in the spinal cord; $\mathrm{D}_{\mathrm{O}}=$ average density of nonneuronal cells per milligram of tissue in the spinal cord; $\mathrm{M}_{\mathrm{BD}}=$ average body mass (in grams); $\mathrm{M}_{\mathrm{SC}} \% \mathrm{M}_{\mathrm{BD}}=$ relative mass of the spinal cord as a percentage of body mass (calculated from averages); $\mathrm{M}_{\mathrm{BR}}=$ average brain mass (in grams) [data from HerculanoHouzel et al., 2007, and Gabi et al., 2008]; $\mathrm{M}_{\mathrm{SC}} \% \mathrm{M}_{\mathrm{CNS}}=$ relative mass of the spinal cord as a percentage of CNS mass (brain + spinal cord; calculated from averages); $\mathrm{N}_{\mathrm{BR}}=$ average number of neurons in the brain (in millions) [data from Herculano-Houzel et al., 2007, and Gabi et al., 2010]; $\mathrm{N}_{\mathrm{SC}} \% \mathrm{~N}_{\mathrm{CNS}}=$ relative number of spinal cord neurons as a percentage of the number of CNS neurons (brain + spinal cord; calculated from averages). 

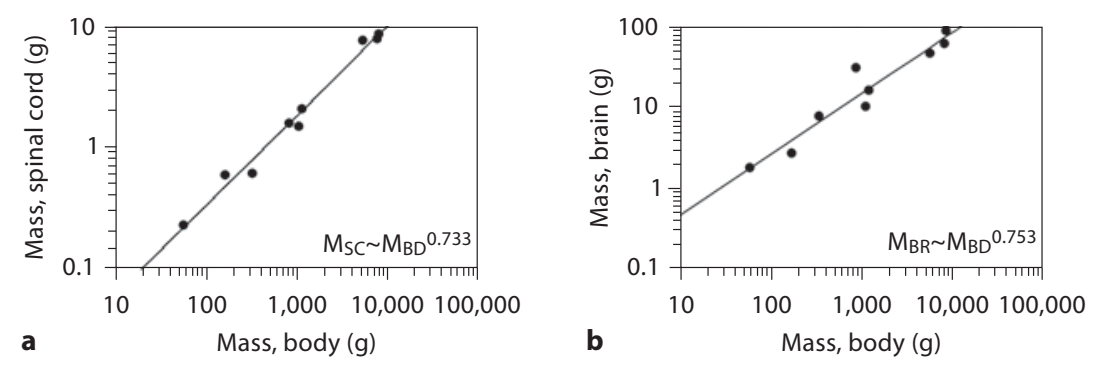

Fig. 3. Spinal cord and brain mass increase as power functions of body mass. Each point represents the average spinal cord (a) or brain mass (b; ordinate) and average body mass (abscissa) for each of 8 primate species and the tree shrew. Plotted lines are power functions calculated for all 9 species, with the exponents indicated (both values of $\mathrm{p}<0.0001$ ). $\mathrm{M}_{\mathrm{BD}}=$ Average body mass; $\mathrm{M}_{\mathrm{BR}}=$ average brain mass. $\mathrm{M}_{\mathrm{SC}}=$ average mass of spinal cord.
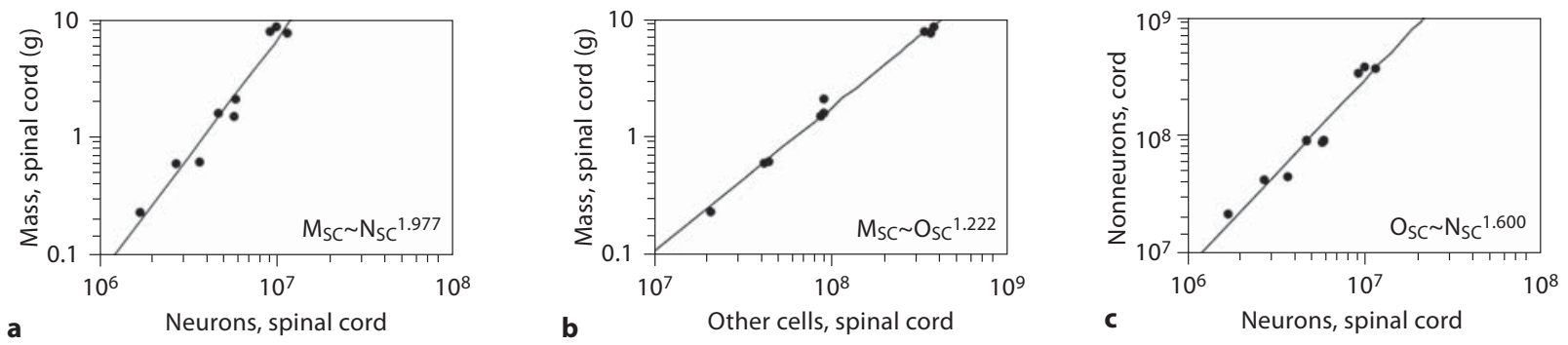

Fig. 4. Cellular scaling rules for the spinal cord. Cord mass (ordinate) increases as power functions of total number of neurons (a) and total number of other (nonneuronal) cells (b) in the spinal cord (abscissa). Each point represents the average values for each of 8 primate species and the tree shrew. c Total number of other cells increases faster than the total number of neurons in the spi- nal cord. Plotted lines are power functions calculated for all 9 species, with the respective exponents indicated (all values of $\mathrm{p}<$ 0.0001). $\mathrm{M}_{\mathrm{SC}}=$ Average mass of spinal cord; $\mathrm{N}_{\mathrm{SC}}=$ average number of neurons in the spinal cord; $\mathrm{O}_{\mathrm{SC}}=$ average number of other (nonneuronal) cells in the spinal cord.

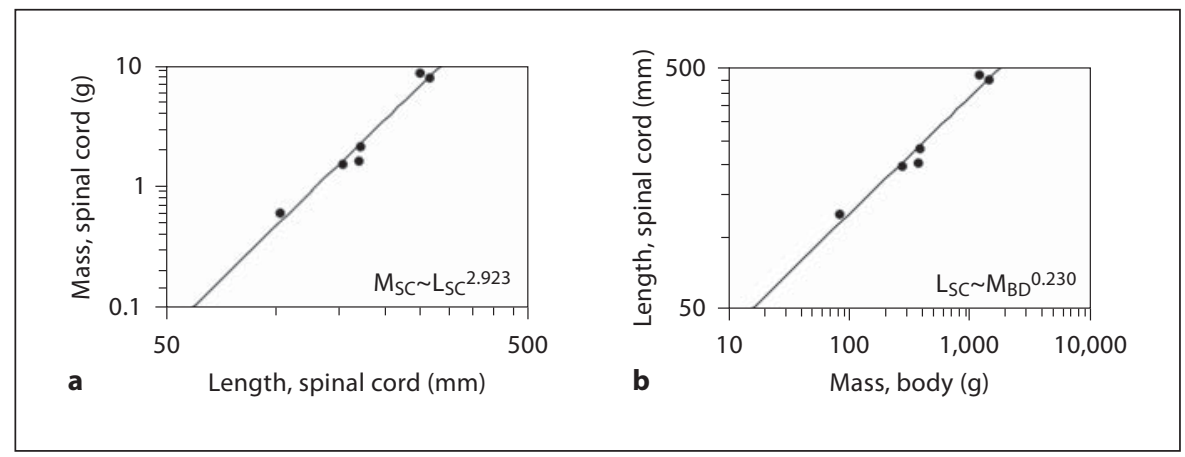

Fig. 5. Spinal cord mass and length scaling. a Spinal cord mass varies with cord length raised to an exponent of close to 3.0. b Spinal cord length varies with body mass raised to an exponent that is significantly smaller than $1 / 3$ (95\% CI, 0.171-0.289). Each point represents the average values available for each of 5 pri- mate species and the tree shrew. Plotted lines are power functions calculated for all 6 species, with the exponents indicated $\left(\mathrm{p}=0.0005\right.$ and $\mathrm{p}=0.0004$, respectively). $\mathrm{L}_{\mathrm{SC}}=$ Average length of spinal cord; $\mathrm{M}_{\mathrm{BD}}=$ average body mass; $\mathrm{M}_{\mathrm{SC}}=$ average mass of spinal cord. 

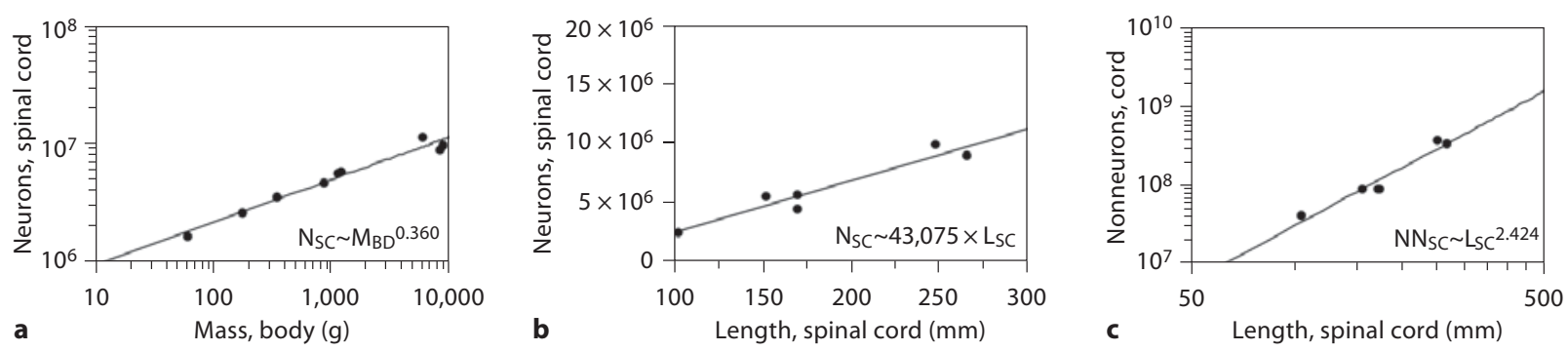

Fig. 6. Cellular composition of the spinal cord scales with cord length. The total number of spinal cord neurons increases with body mass raised to the power of 0.360 , close to $1 / 3$ (a), and as a linear function of spinal cord length (b), with on average 43,075 neurons per millimeter. In contrast, the total number of other (nonneuronal) cells in the spinal cord increases as a steep power function of cord length (c). Each point represents the average val- ue for each of 8 primate species and the tree shrew. Plotted power $(\mathbf{a}, \mathbf{c})$ or linear (b) functions were calculated for all 9 species, and the respective exponents $(\mathbf{a}, \mathbf{c})$ or constant $(\mathbf{b})$ are indicated $(\mathrm{p}<$ $0.0001 ; \mathrm{r}^{2}=0.918, \mathrm{p}=0.0004 ;$ and $\mathrm{p}=0.0014$ for $\mathbf{a}-\mathbf{c}$, respectively). $\mathrm{L}_{\mathrm{SC}}=$ Average length of spinal cord; $\mathrm{M}_{\mathrm{BD}}=$ average body mass; $\mathrm{N}_{\mathrm{SC}}=$ average number of neurons in the spinal cord; $\mathrm{NN}_{\mathrm{SC}}=$ average number of nonneurons in the spinal cord.

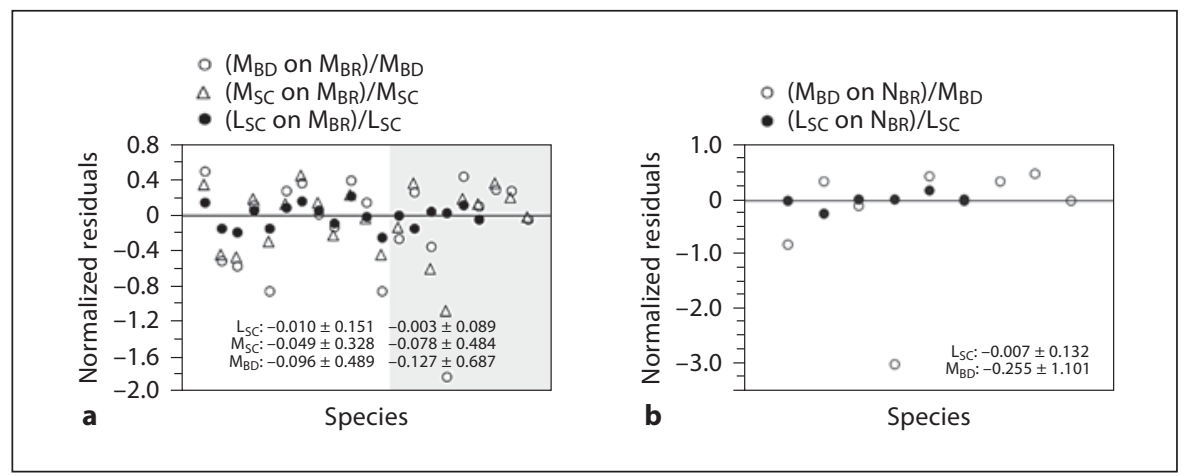

Fig. 7. Spinal cord length is more directly related than body mass to brain mass and number of neurons. a Normalized residuals for body mass (open circles), spinal cord mass (open triangles) and spinal cord length (filled circles) calculated onto brain mass for primate species in our dataset (gray area) and in an independent dataset [MacLarnon, 1996]. b Normalized residuals for brain mass (open circles) and spinal cord length (filled circles) calculated onto number of brain neurons for the primate species in our dataset. Mean residuals and standard errors are indicated for each dataset. $\mathrm{L}_{\mathrm{SC}}=$ Average length of spinal cord; $\mathrm{M}_{\mathrm{BD}}=$ average body mass; $\mathrm{M}_{\mathrm{BR}}=$ average brain mass; $\mathrm{M}_{\mathrm{SC}}=$ average mass of spinal cord; $\mathrm{N}_{\mathrm{BR}}=$ average number of neurons in the brain. rons per linear millimeter of spinal cord does not covary significantly with cord length or with cord mass (Spearman correlation, $p=0.3379$ and 0.1797 , respectively). In contrast to the invariant number of neurons per millimeter of spinal cord, the total number of nonneuronal cells increases steeply with cord length (raised to the power of 2.424; CI, 1.564-3.285; fig. 6c).

The finding that the spinal cord cellular composition scales with cord length raises the intriguing possibility that variations in brain mass and composition across species are primarily related to cord length, rather than body mass. To examine this possibility, we compared the residuals of body mass, cord mass and cord length regressed onto brain mass (normalized for body mass, cord mass and cord length, respectively) for each of the species in our sample and in a previous dataset [MacLarnon, 1996]. In both datasets, we find that the smallest normalized residuals are obtained for cord length (fig. 7a; our dataset, cord length $\times$ body mass, $\mathrm{p}=$ 0.0067; cord length $\times$ cord mass, $p=0.0184$; MacLarnon dataset, $\mathrm{p}=0.0243$ and $\mathrm{p}=0.0153$, respectively; Mann-Whitney comparison of the absolute values of the 


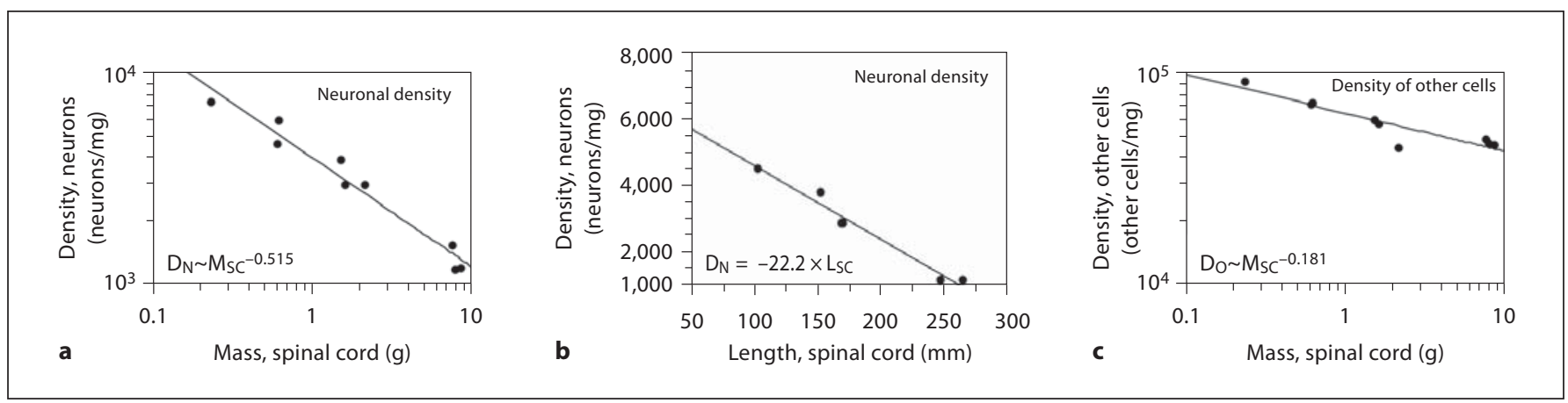

Fig. 8. Scaling of neuronal and nonneuronal densities in the spinal cord. a, b Neuronal density in the spinal cord, calculated as the number of neurons per milligram of spinal cord, decreases with approximately the square root of spinal cord mass (a; $\mathrm{p}<$ $0.0001)$, and decreases linearly with increasing cord length (b; $\left.r^{2}=0.971, p=0.0003\right)$. Each point represents the average values for each of 8 primate species and the tree shrew. c Nonneuronal density in the spinal cord, calculated as the number of nonneuronal cells/mg of spinal cord, decreases as a power function of increasing spinal cord mass $(\mathrm{p}=0.0004) . \mathrm{D}_{\mathrm{N}}=$ average density of neurons per milligram of tissue in the spinal cord; $\mathrm{D}_{\mathrm{O}}=$ average density of other (nonneuronal) cells per milligram of tissue in the spinal cord; $\mathrm{L}_{\mathrm{SC}}=$ average length of spinal cord; $\mathrm{M}_{\mathrm{SC}}=$ average mass of spinal cord.
Fig. 9. Intraspecific scaling of nonneuronal density in the spinal cord. Nonneuronal density in the spinal cord, calculated as the number of nonneuronal cells per milligram of spinal cord, decreases as similar power functions of increasing spinal cord mass across tree shrew, galago and owl monkey individuals. Each line represents the power function within a species, with exponents indicated above $(\mathrm{p}=0.0088, \mathrm{p}=0.0221$ and $\mathrm{p}=0.0010$, respectively). Each point represents 1 individual.

normalized residuals). Similarly, we find smaller normalized residuals of cord length than of body mass onto brain number of neurons in our dataset (fig. $7 \mathrm{~b}, \mathrm{p}=$ 0.0451, Mann-Whitney comparison of absolute residuals). These findings indicate that brain mass and neuronal composition are more directly related to spinal cord length than to body mass, and body mass seems free to vary to a much larger extent.

\section{Cell Densities Decrease in Larger Spinal Cords}

The large exponent of 1.977 relating spinal cord mass to number of neurons, well above linearity, suggests that average neuronal cell size (which includes the soma, axon

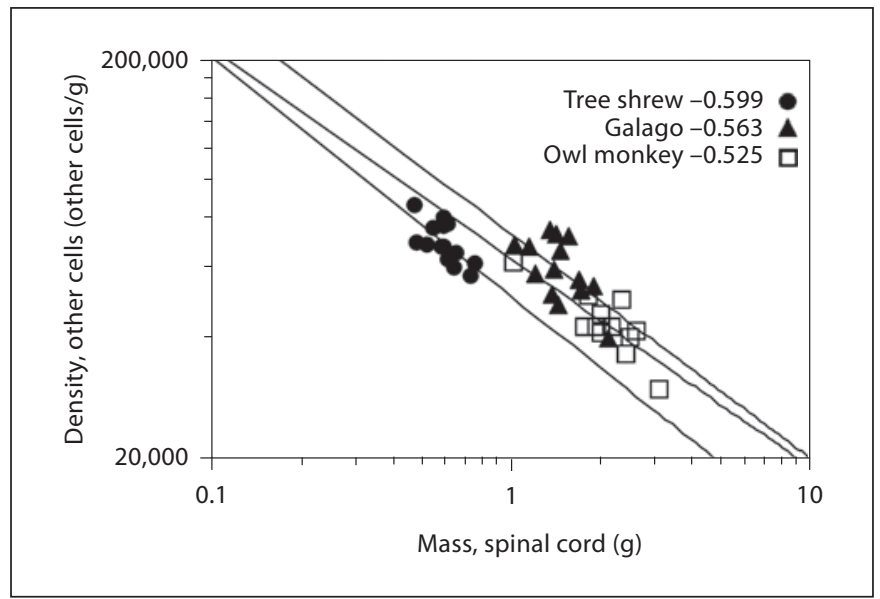

and all dendrites) increases rapidly in the spinal cord as it gains neurons. Considering that cord mass varies with the product of its number of neurons and average neuronal mass, and assuming that the latter varies as a power function of the number of neurons, the exponent of this function can be estimated as $1.977-1=0.977$. The proximity to linearity suggests that average neuronal size increases in the spinal cord proportionally with its number of neurons, and therefore also linearly with cord length. Consistently with the expected increase in average neuronal size, neuronal density decreases rapidly as a function of increasing cord mass, with an exponent of -0.515 (CI, -0.611 to -0.420 ; fig. $8 \mathrm{a}$ ). Neuronal density decreases 
Fig. 10. Brain mass increases linearly with cord mass. Graphs depict how the mass of the whole brain (a), cerebral cortex (b), cerebellum (c) and remaining areas of the brain (d) scale as power functions of spinal cord mass with exponents close to 1.0 or slightly below 1.0. Each point represents the average values for each of eight primate species and the tree shrew. Plotted lines are power functions calculated for all 9 species, with the respective exponents indicated $(\mathrm{p}<0.0001, \mathrm{p}<0.0001, \mathrm{p}=0.0004$ and $\mathrm{p}=0.0003$, respectively). $\mathrm{M}_{\mathrm{BR}}=$ Average brain mass; $\mathrm{M}_{\mathrm{CB}}=$ average mass of the cerebellum; $\mathrm{M}_{\mathrm{CX}}=$ average mass of the cortex; $M_{R A}=$ average mass of the remaining areas; $\mathrm{M}_{\mathrm{SC}}=$ average mass of spinal cord.

Fig. 11. Numbers of neurons in the brain, cerebral cortex and cerebellum increase faster than number of neurons in the spinal cord. Graphs depict how numbers of neurons in the whole brain (a), cerebral cortex (b), cerebellum (c) scale as power functions of the number of neurons in the spinal cord with exponents well above 1.0, while the number of neurons in the remaining areas (d) scales approximately linearly with the number of neurons in the spinal cord. Each point represents the average values for each of eight primate species and the tree shrew. Plotted lines are power functions calculated for all 9 species, with the respective exponents indicated $(\mathrm{p}=0.0009, \mathrm{p}=0.0017, \mathrm{p}=0.0007$ and $\mathrm{p}=0.0041$, respectively). $\mathrm{N}_{\mathrm{BR}}=$ Average number of neurons in the brain; $\mathrm{N}_{\mathrm{CB}}=$ average number of neurons in the cerebellum; $\mathrm{N}_{\mathrm{CX}}=$ average number of neurons in the cortex; $\mathrm{N}_{\mathrm{RA}}=$ average number of neurons in the remaining areas; $\mathrm{N}_{\mathrm{SC}}=$ average number of neurons in the spinal cord.
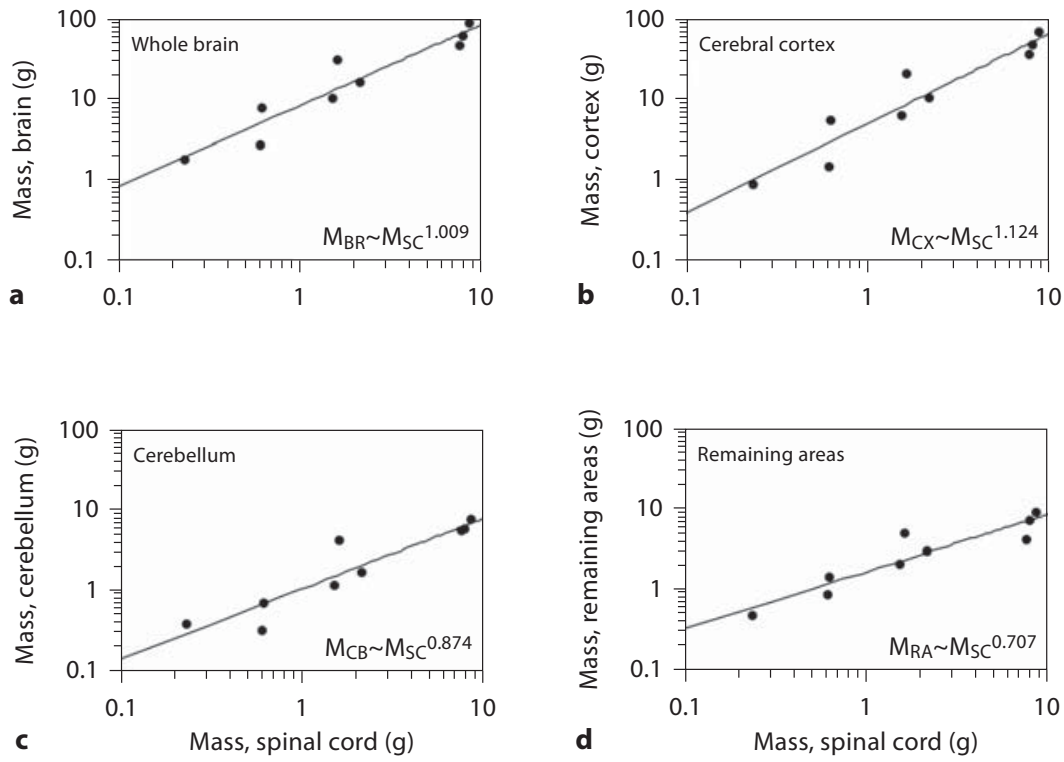
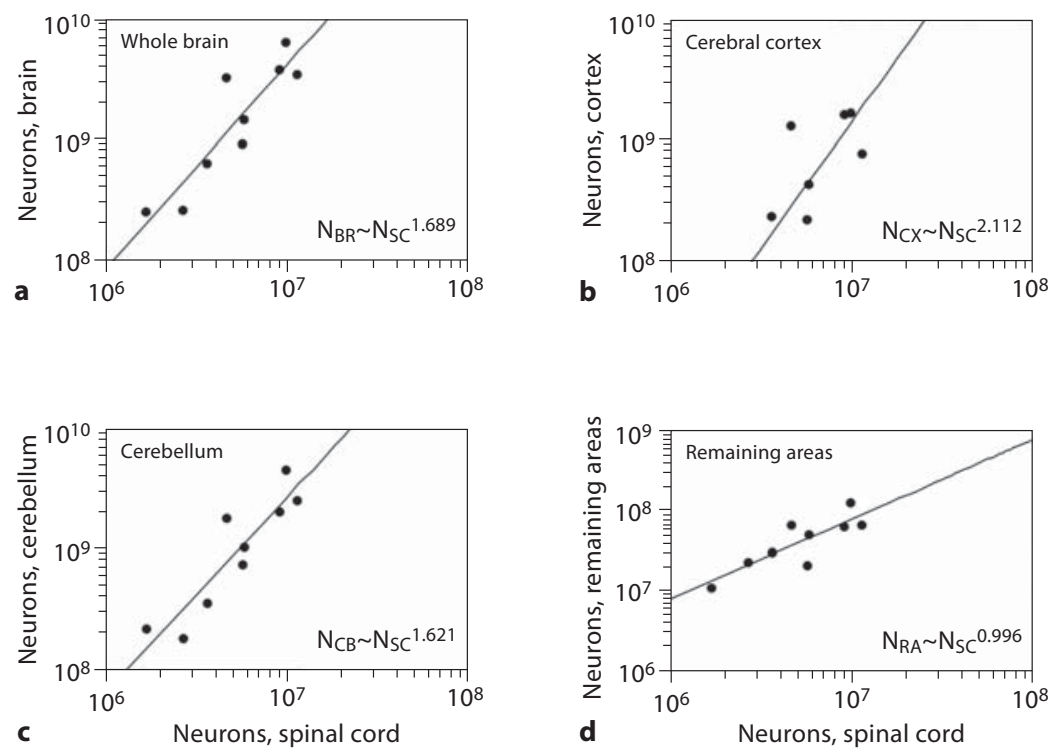
Table 3. Deviations from expected cellular composition of the spinal cord

Expected Observed Deviation ${ }^{\mathrm{a}}$

Number of neurons expected for cord mass,

$N_{S C}=3,862,871.316 \times M_{S C} 0.484$

$\begin{array}{lrrr}\text { Microcebus murinus } & 1.92 \times 10^{6} & 1.68 \times 10^{6} & -12.3 \% \\ \text { Tupaia glis } & 3.03 \times 10^{6} & 2.69 \times 10^{6} & -11.3 \% \\ \text { Callithrix jacchus } & 3.07 \times 10^{6} & 3.65 \times 10^{6} & 19.0 \% \\ \text { Sciureus carolinensis } & 4.36 \times 10^{6} & 5.70 \times 10^{6} & 30.7 \% \\ \text { Saimiri sciureus } & 4.85 \times 10^{6} & 4.69 \times 10^{6} & -3.3 \% \\ \text { Otolemur garnetti } & 4.74 \times 10^{6} & 5.73 \times 10^{6} & 20.8 \% \\ \text { Aotus trivirgatus } & 5.57 \times 10^{6} & 5.82 \times 10^{6} & 4.5 \% \\ \text { Macaca fascicularis } & 10.24 \times 10^{6} & 11.38 \times 10^{6} & 11.1 \% \\ \text { Macaca radiata } & 10.47 \times 10^{6} & 9.06 \times 10^{6} & -13.4 \% \\ \text { Macaca mulatta } & 10.89 \times 10^{6} & 10.00 \times 10^{6} & -8.2 \%\end{array}$

Number of nonneurons expected for cord mass,

$N N_{S C}=63,289,496.243 \times M_{S C} 0.811$

Microcebus murinus $19.56 \times 10^{6}$

Tupaia glis

Callithrix jacchus

Sciureus carolinensis

Saimiri sciureus

Otolemur garnetti

Aotus trivirgatus

Macaca fascicularis

Macaca radiata

$42.22 \times 10^{6}$

$43.00 \times 10^{6}$

$77.56 \times 10^{6}$

$92.75 \times 10^{6}$

$89.26 \times 10^{6}$

$116.90 \times 10^{6}$

$21.27 \times 10^{6}$

$41.96 \times 10^{6}$

$44.55 \times 10^{6}$

$69.72 \times 10^{6}$

$91.24 \times 10^{6}$

$88.47 \times 10^{6}$

$91.00 \times 10^{6}$

$324.31 \times 10^{6} 360.62 \times 10^{6}$

$336.29 \times 10^{6} 335.94 \times 10^{6}$

$359.37 \times 10^{6} 379.71 \times 10^{6}$

$8.8 \%$

$-0.6 \%$

$3.6 \%$

$-10.1 \%$

$-1.6 \%$

$-0.9 \%$

$-22.2 \%$

$11.2 \%$

$-0.1 \%$

Macaca mulatta

${ }^{\text {a }}$ Deviation $=100 \times($ observed - expected $) /$ expected .

linearly with cord length $\left(r^{2}=0.971, p=0.0003\right.$; fig. $\left.8 b\right)$, which is in line with the linear increase in neuronal cell size with number of neurons predicted above. Nonneuronal density also varies as a power function of cord mass but with a smaller exponent of -0.181 (CI, -0.247 to -0.114 ; fig. 8c).

\section{Intraspecies Spinal Cord Comparisons}

We collected a substantial number of spinal cords from 3 species: tree shrews $(n=14)$, galagos $(n=15)$, and owl monkeys $(\mathrm{n}=12)$. These numbers were sufficient to investigate changes in the spinal cord within each species (table 3). Although body mass was significantly larger in male than in female tree shrews and galagos (by 17 and $37 \%$, respectively; Mann-Whitney $U$ test, $\mathrm{p}=0.0449$ and $\mathrm{p}=0.0051$ ), no significant differences were found between males and females in all 3 species in spinal cord mass, total number of neurons or nonneurons, or the percentage of cells that were neurons (Mann-Whitney, all values of $\mathrm{p}>0.05$; not shown). No significant age correla- tions were found either, as we compared age to spinal cord mass, total number of neurons and nonneurons, and the percentage of cells that were neurons (Spearman correlation, $\mathrm{p}>0.05$ ).

Within each species, the mass of the spinal cord varied between the largest and smallest cords by $1.7 \times$ in tree shrews, $2.0 \times$ in galagos, and $3.1 \times$ in owl monkeys. This variation, however, was not significantly correlated with intraspecific variation in numbers of neurons or nonneuronal cells in the spinal cord or with individual body size (Spearman correlation, all $\mathrm{p}>0.05$ ), except that cord mass varied among owl monkey individuals as a power function of the number of nonneuronal cells with an exponent of 1.332 ( $p=0.0024$; not shown), close to the exponent of 1.222 that applies across species. Within each of the 3 species, the density of nonneuronal cells in the spinal cord was found to vary as a power function of spinal cord mass with similar exponents of $-0.599,-0.563$ and $-0.525(\mathrm{p}=0.0068,0.0221$ and 0.0010 , for tree shrew, galago and owl monkey, respectively; fig. 9) while neuronal density in the cord covaried significantly with cord mass only across owl monkeys (exponent $-0.890, \mathrm{p}=$ 0.0003; not shown).

\section{Spinal Cord Relationships with the Brain}

We were interested in examining how brain cellular composition scales with the spinal cord. For suitable brain data sets, we chose those of Herculano-Houzel et al. [2007] and Gabi et al. [2010, this issue] because they used identical methods. The spinal cord and combined brain data sets have 9 species in common: mouse lemur, tree shrew, galago, common marmoset, owl monkey, squirrel monkey, bonnet monkey, long-tailed monkey and rhesus macaque. As mentioned above, brain mass and spinal cord mass are linearly correlated (fig. 10a). As a result, spinal cord mass represents on average $11.2 \pm 3.8 \%$ of total CNS mass, and this value does not covary with body or CNS mass (Spearman correlation, $\mathrm{p}=0.7773$ and $\mathrm{p}=$ 0.4229 , respectively).

When the brain is separated into cerebral cortex (including white matter), cerebellum and rest of the brain (without the olfactory bulb), cortical mass is found to increase slightly faster than spinal cord mass (as a power function with exponent 1.124; CI, 0.789-1.460; fig. 10b), cerebellar mass increases slightly slower than spinal cord mass (as a power function of cord mass with an exponent of 0.874; CI, 0.550-1.198; fig. 10c) and the mass of the rest of the brain increases more slowly than spinal cord mass (as a power function of cord mass with exponent of 0.707; CI, 0.461-00.953; fig. 10d). 
Scaling relationships between numbers of neurons in the brain and spinal cord are, however, strikingly different from the mass relationships above. This difference can be illustrated by the finding that while the macaque monkey contains $6 \times$ more neurons in the spinal cord than the mouse lemur, its brain has $25 \times$ more neurons than the mouse lemur brain (table 1). Overall, the number of neurons in the brain scales with the number of neurons in the spinal cord raised to an exponent of 1.689 (CI, 0.965-2.414; fig. 11a). As a result, the fraction of CNS neurons in the spinal cord decreases from at most $1 \%$ in smaller animals to close to $0.1 \%$ in larger animals, varying with CNS mass raised to the power of -0.427 (CI, -0.659 to -0.194$)$. The number of neurons in the cerebral cortex increases very rapidly as the spinal cord gains neurons, varying as a power function of average number of neurons in the spinal cord with an exponent of 2.112 (CI, 1.099-3.124; fig. 11b). The number of neurons in the cerebellum also increases much faster than the number of neurons in the spinal cord as a power function of average number of neurons in the spinal cord with an exponent of 1.621 (CI, 0.953-2.289; fig. 11c). In contrast, the number of neurons in the remaining areas, which include the entire brainstem up to the basal ganglia, increases practically linearly with the number of neurons in the spinal cord (power function exponent, 0.996; CI, 0.423-1.559; fig. 11d).

\section{Discussion}

Previous studies have argued that the spinal cord scales with body surface area [Jerison, 1977; MacLarnon, 1996], with body mass [Krompecher and Lipak, 1996], with the amount of fat-free body mass [Schoenemann, 2004] or with metabolic rate [Martin, 1981], varying in mass as a function of body mass raised to exponents of $2 / 3,1,3 / 4$, or $3 / 4$, respectively. Similar inconsistencies are found across studies relating brain mass and body mass, including our own [Herculano-Houzel et al., 2007]. Given these inconsistencies among studies, which show that body-CNS mass relations are strongly dependent on the different species sampled and may be affected by great variations in body size, no consensus has yet been reached in the literature regarding how the spinal cord scales in mass with body size. In the present study, we find cord mass to scale with body mass raised to the power of 0.733 , close to $3 / 4$, supporting the metabolic and fat-free body mass hypotheses of spinal cord scaling. This exponent, however, might also derive from a simpler event in development: the failure of the spinal cord to continue extending with body length over the full course of body growth [Barson, 1970; Kuhlenbeck, 1975], as detailed below.

Because of the position of the spinal cord as an obligatory interface between the brain and most of the body, the neuronal composition of the spinal cord can be expected to indicate how much neuronal demand is created by body size, and is therefore a more functionally relevant parameter than cord mass in allometric studies. We find that the number of neurons in the spinal cord varies with body mass raised to an exponent that is much smaller than expected, with a value of 0.360 , close to $1 / 3$, for the primate species we analyzed. This exponent suggests that the neuronal composition of the spinal cord correlates with body length, which varies as the $1 / 3$ power of body mass. Indeed, we show that, rather than directly reflecting body mass, surface area or lean mass, the number of neurons in the spinal cord is a linear function of cord length, with an estimated average of 43,000 neurons per millimeter of spinal cord (although variations are to be expected, for instance at the cervical and lumbar enlargements). This relationship suggests that the much simpler constraint of body length, which will correspond to the length of the vertebral canal formed during development, determines the extension and number of neurons that compose the spinal cord of an animal. The finding that actual cord length varies with body mass raised to an exponent of 0.230 , smaller than the expected $1 / 3$ and similar to previous findings of $0.22-0.24$ in primates [MacLarnon, 1996], can be explained by the fact that the spinal cord does not occupy the entire length of the adult vertebral canal since the latter continues to extend with body length past the point in development when the spinal cord is fully formed [Barson, 1970; Kuhlenbeck, 1975].

Most importantly, our analysis of residuals indicates that spinal cord length is a better correlate of both brain mass and brain number of neurons than body mass is. We find similar results applying this analysis to an independent dataset [MacLarnon, 1996], despite the significantly different slopes relating spinal cord mass to body mass in our dataset (0.733) and in hers (0.66). Since body mass seems much more variable than cord length in regard to brain composition, we suggest that body mass, although traditionally considered a direct correlate or even a determinant of brain mass, may be only incidentally correlated with brain mass because of the relationship between body mass and body length, and hence spinal cord length. We do not suggest that cord length is a determinant of brain 
growth; rather, we argue that our analysis of residuals is compatible with the existence of more closely related developmental parameters that drive spinal cord and brain formation than those that relate growth of the CNS to growth of the body.

\section{Spinal Cord Neuronal Scaling Rules}

The discrepancy between the scaling of cord mass with body mass and of cord number of neurons with body mass can be explained by the finding that cord mass does not increase linearly with its number of neurons, but rather as a function of this parameter raised to the power of 1.977, which implies that average neuronal size in the spinal cord increases with number of neurons raised to the power of 0.977 , that is, it increases almost linearly with the number of neurons. If soma and dendritic arborization size are only a small proportion of total neuronal size in the spinal cord, this scaling relationship can be illustrated by considering that a 10 -fold longer spinal cord would have 10-fold longer neurons (whose axons would occupy mostly the white matter). Our results are consistent with the independent observation that the length of central somatosensory pathways in humans is proportional to subject height [Ozaki et al., 1994]. An increase in average neuronal size proportionally to cord length is in line with the columnar organization of the spinal cord and the subsequent need for individual axons to become longer in order to convey signals to and from more distant positions in a longer cord in larger animals. Alternatively, the average width of the axons in the spinal cord might become larger in longer spinal cords; or neurons might have more connections and hence branch more, which would also increase their average size. The increased branching scenario, however, is inconsistent with our finding that the number of nonneuronal cells increases more slowly than expected for the increase in number of neurons (see below). Examining these alternatives will require a separate study of the scaling of spinal cord gray and white matter.

\section{Spinal Cord Nonneuronal Scaling Rules}

Nonneuronal cells are the vast majority of the cells that compose the spinal cord, as expected of a structure that is mostly comprised of white matter, including myelinated fibers. The isotropic fractionator technique allows us to quantify the number of cell bodies of neurons and nonneurons in our sample, and thus this study only examines cells in which the soma is contained within the spinal cord. Therefore, the neurons in our data set come from the dorsal, intermediate and ventral horns of the gray matter, which include cells related to interoception, preganglionic autonomic neurons, the motor system, intrinsic spinal systems such as reflex arc neurons and spinal pattern generators, and a portion of the proprioceptive inputs from the body [Willis and Coggeshall, 1978]. Thus, cord mass includes a number of fibers, such as those in the corticospinal and dorsal column tracts, whose neuronal cell nuclei are not included, as their soma are located in the cortex and dorsal root ganglia, respectively. In contrast, soma for supporting cells such as glia and vascular cells are found in both the gray and the white matter of the spinal cord. Thus neurons of the corticospinal tracts and dorsal columns are not counted, but the nonneurons participating in their pathways are.

A complete examination of white matter neurons would require an extensive analysis of axons. That analysis would have its own complications in calculating neuron number in the spinal cord, however, as it would be difficult to locate the origins of each axon (from intrinsic or extrinsic spinal neurons) or the presence of axon collaterals. Previous studies have instead examined the cross-sectional area of component parts of the white matter, and have found that the corticospinal tract decreases in size relative to body mass [Towe, 1973]. Additionally, tracer labeling studies into the $\mathrm{C} 1 / \mathrm{C} 2$ vertebrae suggest that the corticospinal system decreases in size relative to body weight but is a linear function of brain weight [Nudo and Masterton, 1990] while the tectospinal tract is highly variable between species [Nudo and Masterton, 1989].

Considering that the average neuronal length increases linearly with the number of neurons, and that the increased neuronal length consists presumably of longer axons in the white matter, the number of oligodendrocytes necessary to myelinate these longer and more numerous fibers would be expected to increase with the number of neurons in the cord raised to the power of 2 . The fact that this exponent is smaller, with a value of 1.6, is compatible with at least three, not mutually exclusive, alternative scenarios: that the average size of the myelinating oligodendrocytes increases in larger spinal cords, that the average axon diameter increases in larger spinal cords (such that the increase in total length of axons to be myelinated increases with the number of neurons raised to an exponent that is smaller than 1), and that a decreasing fraction of fibers are myelinated in larger spinal cords.

An increasing average size of the nonneuronal cells is compatible with the smaller nonneuronal cell densities observed in larger spinal cords although the smaller den- 
sities could also be explained if a larger fraction of the tissue volume in larger cords were composed of fibers, with nonneuronal cells of constant size, as we have proposed to be the case in the primate brain [HerculanoHouzel et al., 2007]. This scenario would also be compatible with an increase in the diameter of the widest axons in larger cords, as seems to be the case in other CNS white matter tracts such as the corpus callosum, which presumably minimizes conduction times over longer distances [Olivares et al., 2001; Wang et al., 2008]. Finally, if a decreasing fraction of fibers are myelinated in larger spinal cords, fewer additional oligodendrocytes would be required; one possibility is that more neurons are involved in local connections in larger spinal cords, as proposed in larger brains [Changizi et al., 2001], and these short-range connections may not require as many supporting nonneuronal cells.

\section{Tree Shrew}

The last common ancestor of all 8 primates in our sample lived approximately 55 million years ago [Purvis, 1995], the last common ancestor of the primates and tree shrews lived approximately 85 million years ago, and the last common ancestor of primates, tree shrews, and rodents lived approximately 90 million years ago [Liu et al., 2001; Murphy et al., 2001a, b; Huchon et al., 2002; Springer et al., 2003]. In an earlier study on brain scaling [Herculano-Houzel et al., 2007], addition of the tree shrew to the primate data set did not significantly alter the cellular scaling rules observed, suggesting that the tree shrew scales similarly to primates. Interestingly, the tree shrew also fits the rodent scaling rules [Herculano-Houzel S., unpublished observations], suggesting that the separation of primates from rodent scaling rules may have occurred after the divergence of primate and tree shrew ancestors.

\section{Intraspecies Comparisons}

We find that variations in spinal cord mass among individuals of the same primate species are not related to variations in the numbers of neurons, and are related to variations in the number of nonneuronal cells only in owl monkeys. On the other hand, intraspecific variations in cord mass were related to variations in the density of nonneuronal cells in all three species examined. While the range of intraspecific variation is too small to rule out the conformity to the scaling rules that apply to interspecific variation, the finding that a similar exponent relates nonneuronal density to cord mass across individuals of 3 species suggests that different rules govern intraspecies vari- ability, and that variation across individuals in cell size, rather than in the number of cells, might be at play. We are currently examining this possibility in species with a larger range of variation across individuals.

\section{Spinal Cord-Brain Scaling}

A major finding in the present study is that the mass relationships between spinal cord and brain do not reflect the relationships between numbers of neurons in these structures. Indeed, while the spinal cord represents about $11 \%$ of CNS mass, regardless of body or brain size, it holds a tiny percentage of all CNS neurons, decreasing from at most $1 \%$ to about $0.1 \%$ with increasing CNS and body size, and an absolute number of only 1-10 million neurons in the primate species examined.

The decreasing percentage of CNS neurons located in the spinal cord results from the faster increase in numbers of neurons in the brain than in the spinal cord although these structures gain mass proportionately to one another, with an exponent of 1.009 , which is close to that of 1.17 reported for an independent dataset [MacLarnon, 1996]. Interestingly, the finding that the number of neurons in the ensemble of brain stem, diencephalon, and basal ganglia scales linearly with the number of neurons in the spinal cord suggests that the computational power of these structures increases hand in hand with the brainbody interface provided by the number of neurons in the spinal cord. In contrast, the cerebral cortex and the cerebellum gain neurons at a remarkably faster rate than the spinal cord, increasing as a function of the number of cord neurons raised to the powers of 2.112 and 1.621, respectively. These exponents are, however, not significantly different from each other, a finding that is compatible with our recent observation that the number of neurons in the cerebral cortex and cerebellum scale coordinately across all mammalian species examined so far [Herculano-Houzel, 2010]. This faster increase in cortical and cerebellar neurons relative to the spinal cord presumably allows for the addition of great complexity to the processing of bodily and environmental information, well in line with current ideas on the evolution of the mammalian nervous system [Byrne and Whiten, 1988; Barton and Dunbar, 1997; Clark et al., 2001].

\section{Acknowledgments}

For the generous donation of spinal cords, we thank Tom Norton, Jeff Schall, Troy Hackett, Vivien Casagrande, Anna Roe, Christine Collins, Peiyan Wong, Iwona Stepniewska, Omar Gharbawie, Jamie Reed, Huixin Qi, Peter Kaskan and Corrie Camalier. 
We thank Charnese Bowes and Omar Gharbawie for assistance with surgical procedures, Victor Luria for comments on the manuscript and Bruno Mota for mathematical considerations.

Grant sponsor: National Institute of General Medical Studies for the Vanderbilt Medical-Scientist Training Program, Public
Health Service Award T32 GM07347 (M.J.B.), FAPERJ-Jovem Cientista (S.H.-H.), CNPq-Edital Universal (S.H.-H.), National Institutes of Health grant number NS 16446 (J.H.K.), National Eye Institute grant number 002686 (J.H.K.).

\section{References}

-Azevedo FA, Carvalho LR, Grinberg LT, Farfel JM, Ferretti RE, Leite RE, Jacob Filho W, Lent R, Herculano-Houzel S (2009): Equal numbers of neuronal and nonneuronal cells make the human brain an isometrically scaled-up primate brain. J Comp Neurol 513:532-541.

Barson AJ (1970): The vertebral level of termination of the spinal cord during normal and abnormal development. J Anat 106:489-497.

Barton RA, Dunbar RIM (1997): Evolution of the social brain; in Whiten AW, Byrne RW (eds): Machiavellian Intelligence. II. Evaluations and Extenstions. New York, Cambridge University Press, pp 240-263.

Burish MJ, Peebles JK, Kaas JH, HerculanoHouzel S (2007): Cellular scaling rules for primate spinal cord. Soc Neurosci Abstr 193.4.

Byrne RW, Whiten A (1988): Machiavellian Intelligence: Social Expertise and the Evolution of Intellect in Monkeys, Apes, and Humans. Oxford, Clarendon Press.

-Changizi MA (2001): Principles underlying mammalian cortical scaling. Biol Cybern 84:207-215.

Clark DA, Mitra PP, Wang SS (2001): Scalable architecture in mammalian brains. Nature 411:189-193.

Gabi M, Collins CE, Wong P, Kaas JH, Herculano-Houzel S (2008): Cellular scaling rules for an extended number of primate species. Soc Neurosci Abstr 79.4.

Gabi M, Collins CE, Wong P, Torres LB, Kaas JH, Herculano-Houzel S (2010): Cellular scaling rules for the brain of an extended number of primate species. Brain Behav Evol 76:32-44.

Felsenstein J (1985): Phylogenies and the comparative method. Am Nat 125:1-15.

Fox JH, Wilczynski W (1986): Allometry of major CNS divisions: towards a reevaluation of somatic brain-body scaling. Brain Behav Evol 28:157-169.

Haug H (1987): Brain sizes, surfaces, and neuronal sizes of the cortex cerebri: a stereological investigation of man and his variability and a comparison with some mammals (primates, whales, marsupials, insectivores, and one elephant). Am J Anat 180:126-142.

Herculano-Houzel S (2010): Coordinated scaling of cortical and cerebellar numbers of neurons. Front Neuroanat 4:12.

-Herculano-Houzel S, Collins CE, Wong P, Kaas $\mathrm{JH}$ (2007): Cellular scaling rules for primate brains. Proc Natl Acad Sci USA 104:35623567.
Herculano-Houzel S, Lent R (2005): Isotropic fractionator: a simple, rapid method for the quantification of total cell and neuron numbers in the brain. J Neurosci 25:2518-2521.

Herculano-Houzel S, Mota B, Lent R (2006): Cellular scaling rules for rodent brains. Proc Natl Acad Sci USA 103:12138-12143.

-Huchon D, Madsen O, Sibbald MJ, Ament K, Stanhope MJ, Catzeflis F, de Jong WW, Douzery EJ (2002): Rodent phylogeny and a timescale for the evolution of Glires: evidence from an extensive taxon sampling using three nuclear genes. Mol Biol Evol 19: 1053-1065.

Jerison HJ (1955): Brain to body ratios and the evolution of intelligence. Science 121:447449.

Jerison HJ (1973): Evolution of the Brain and Intelligence. New York, Academic Press.

Jerison HJ (1977): The theory of encephalization. Ann NY Acad Sci 299:146-160.

Krompecher S, Lipak J (1966): A simple method for determining cerebralization, brain weight and intelligence. J Comp Neurol 127: 113-120.

Kuhlenbeck H (1975): The central nervous system of vertebrates; a general survey of its comparative anatomy with an introduction to the pertinent fundamental biologic and logical concepts. Basel, Karger, vol 4.

Liu FG, Miyamoto MM, Freire NP, Ong PQ, Tennant MR, Young TS, Gugel KF (2001): Molecular and morphological supertrees for eutherian (placental) mammals. Science 291: 1786-1789.

MacLarnon A (1995): The distribution of spinal cord tissues and locomotor adaptation in primates. J Hum Evol 29:463-482.

MacLarnon A (1996): The scaling of gross dimensions of the spinal cord in primates and other species. J Hum Evol 30:71-87.

Maddison WP, Maddison DR (2005): Mesquite: a modular system for evolutionary analysis. Version 2.7. http://mesquite project.org.

Marino L (1998): A comparison of encephalization between odontocete cetaceans and anthropoid primates. Am J Phys Anthropol 97: 339-356.

Martin RD (1981): Relative brain size and basal metabolic rate in terrestrial vertebrates. $\mathrm{Na}$ ture 293:57-60.

Mullen RJ, Buck CR, Smith AM (1992): NeuN, a neuronal specific nuclear protein in vertebrates. Development 116:201-211.
Murphy WJ, Elzirik E, Johnson WE, Zhang YP, Ryder OA, O’Brien SJ (2001): Molecular phylogenetics and the origins of placental mammals. Nature 409:614-618.

Murphy WJ, Eizirik E, O’Brien SJ, Madsen O, Scally M, Douady CJ, Teeling E, Ryder OA, Stanhope MJ, de Jong WW, Springer MS (2001): Resolution of the early placental mammal radiation using Bayesian phylogenetics. Science 294:2348-2351.

Nudo RJ, Masterton RB (1989): Descending pathways to the spinal cord. II. Quantitative study of the tectospinal tract in 23 mammals. J Comp Neurol 286:96-119.

- Nudo RJ, Masterton RB (1990): Descending pathways to the spinal cord. IV. Some factors related to the amount of cortex devoted to the corticospinal tract. J Comp Neurol 296: 584-597.

-Olivares R, Montiel J, Aboitiz F (2001): Species differences and similarities in the fine structure of the mammalian corpus callosum. Brain Behav Evol 57:98-105.

-Ozaki I, Takada H, Baba M, Matsunaga M (1994): Correlation of somatosensory central conduction time with height. Neurology 44: $1115-1119$.

Pagel MD (1992): A method for the analysis of comparative data. J Theor Biol 156:431-442.

Passingham RE (1975): The brain and intelligence. Brain Behav Evol 11:1-15.

Purvis A (1995): A composite estimate of primate phylogeny. Philos Trans R Soc Lond B Biol Sci 348:405-421.

Schoenemann PT (2004): Brain size scaling and body composition in mammals. Brain Behav Evol 63:47-60.

- Springer MS, Murphy WJ, Eizirik E, O’Brien SJ (2003): Placental mammal diversification and the Cretaceous-Tertiary boundary. Proc Natl Acad Sci USA 100:1056-1061.

Towe AL (1973): Relative numbers of pyramidal tract neurons in mammals of different sizes. Brain Behav Evol 7:1-17.

Walker EP, Paradiso JL, Nowak RM (1983): Walker's Mammals of the World, ed 4.Baltimore, Johns Hopkins University Press.

-Wang SS, Shultz JR, Burish MJ, Harrison KH, Hof PR, Towns LC, Wagers MW, Wyatt KD (2008): Functional trade-offs in white matter axonal scaling. J Neurosci 28:4047-4056.

Willis WD, Coggeshall RE (1978): Sensory mechanisms of the spinal cord (New York, Plenum) 